\title{
Intelectuais paranaenses e a Escola Nova, durante a Era Vargas (1930-1945)
}

\section{Paraná intellectuals and the New School, during the Vargas Era (1930-1945)}

\section{Intelectuales paranaenses y la Escuela Nueva, durante la Era Vargas (1930-1945)}

\author{
Alexandra Ferreira Martins Ribeiro ${ }^{1}$ \\ Alboni Marisa Dudeque Pianovski Vieira ${ }^{1}$
}

DOI: http://dx.doi.org/10.20435/serie-estudos.v24i50.1146

\begin{abstract}
Resumo: Os intelectuais, detentores de linguagem própria, fomentaram mudanças culturais, sociais e econômicas, articuladamente com políticas de governo, e no campo da educação, historicamente, vêm ocupando lugar de destaque. Das mudanças promovidas e disseminadas com o auxílio de intelectuais, destaca-se o projeto de renovação da educação brasileira, inspirado pela pedagogia da Escola Nova. Apesar dos ideais escolanovistas terem ganhado força desde as décadas finais do século XIX, no Brasil, a consolidação da pedagogia da Escola Nova ocorreu durante a década de 30 a meados da década de 40 do século XX, durante a chamada Era Vargas. Assim como no restante do país, o Paraná também teve seus intelectuais que atuaram na promoção dessa renovação. O artigo buscou identificar alguns estudos que voltaram seus olhares para intelectuais paranaenses que atuaram em prol da Escola Nova, no período da Era Vargas (1930-1945). Como objetivos específicos, procurou-se compreender alguns aspectos políticos, econômicos e sociais que ocorreram durante o período da Era Vargas (1930-1945), que se conectaram às mudanças ocorridas na educação, e identificar alguns estudos que pesquisaram intelectuais paranaenses que atuaram nesse contexto. A pesquisa possui caráter bibliográfico, fundamentada nos estudos de Miguel (1997); Gomes e Hansen (2016); e Cabral e Magalhães (2016). A metodologia, denominada estado do conhecimento, foi essencial para identificar estudos que se debruçaram acerca das trajetórias de intelectuais paranaenses. A sistematização do conhecimento produzido acerca das trajetórias dos intelectuais contribuiu para alicerçar novas pesquisas, bem como para identificar agentes que auxiliaram na promoção de mudanças no campo da educação.
\end{abstract}

Palavras-chave: História da Educação; Era Vargas; Escola Nova; intelectuais paranaenses.

Abstract: The intellectuals, holders of their own language, have fostered cultural, social and economic changes, articulated with government policies, and in the field of Education, historically they have occupied a prominent place. Of the changes, promoted and disseminated with the

\footnotetext{
${ }^{1}$ Pontifícia Universidade Católica do Paraná (PUC-PR), Curitiba, Paraná, Brasil.
} 
help of intellectuals, stands out the project of renewal of the Brazilian Education inspired by the pedagogy of the New School. Although escolanovista ideals had gained strength since the late nineteenth century, in Brazil the consolidation of New School pedagogy occurred during the 1930s to the mid-1940s during the so-called Era Vargas. As in the rest of the country, Paraná also had its intellectuals who worked to promote this renewal. The article sought to identify some studies that turned their attention to the intellectuals of Paraná who worked for the New School in the period of the Era Vargas (1930-1945). As specific objectives, it was tried to understand some political, economic and social aspects that occurred during the period of Vargas Era (1930-1945) that connected with changes occurred in Education; and to identify some studies that investigated intellectuals from Paraná who acted in this context. The research has a bibliographic character, based on the studies of Miguel (1997); Gomes and Hansen (2016); and Cabral and Magalhães (2016). The methodology called the state of knowledge was essential to identify studies that dealt with the trajectories of intellectuals from Paraná. The systematization of the knowledge produced about the trajectories of the intellectuals contributes to the foundation of new research, as well as helps to identify agents who have helped to promote changes in the field of Education.

Keywords: History of Education; Era Vargas; New School; intellectuals from Paraná.

Resumen: Los intelectuales, poseedores de lenguaje propio, han fomentado cambios culturales, sociales y económicos, articuladamente con políticas de gobierno, y en el campo de la Educación, históricamente vienen ocupando un lugar destacado. De los cambios, promovidos y diseminados con el auxilio de intelectuales, se destaca el proyecto de renovación de la Educación brasileña inspirado por la pedagogía de la Escuela Nova. A pesar de que los ideales escogiantes han ganado fuerza desde las décadas finales del siglo XIX, en Brasil la consolidación de la pedagogía de la Escuela Nueva ocurrió durante la década del 30 a mediados de la década del 40 del siglo XX, durante la llamada Era Vargas. Así como en el resto del país, el Paraná también tuvo sus intelectuales que actuaron en la promoción de esa renovación. El artículo buscó identificar algunos estudios que volvieron sus miradas hacia intelectuales paranaenses que actuaron en pro de la Escuela Nova, en el período de la Era Vargas (1930-1945). Como objetivos específicos se buscó comprender algunos aspectos políticos, económicos y sociales que ocurrieron durante el período de la Era Vargas (19301945) que se conectaron con cambios ocurridos en la Educación; e identificar algunos estudios que investigaron intelectuales paranaenses que actuaron en ese contexto. La investigación tiene carácter bibliográfico, fundamentada en los estudios de Miguel (1997); Gomes y Hansen (2016); y Cabral y Magallanes (2016). La metodología denominada estado del conocimiento fue esencial para identificar estudios que se abordaron acerca de las trayectorias de intelectuales paranaenses. La sistematización del conocimiento producido sobre las trayectorias de los intelectuales contribuye a fundamentar nuevas investigaciones, así como ayuda a identificar agentes que ayudaron en la promoción de cambios en el campo de la Educación.

Palabras clave: Historia de la Educación; Era Vargas; Escuela Nueva; intelectuales paranaenses. 


\section{INTRODUÇÃO}

$\mathrm{Na}$ educação, muitos são os sujeitos envolvidos, tanto como produtores das propostas pedagógicas, quanto como disseminadores ou adaptadores desses conceitos. Dentre esses sujeitos, os intelectuais ocupam lugar de destaque no campo da educação. Para o estudo dos intelectuais e suas propostas pedagógicas no campo da educação, segundo Viñao (1995), pode-se utilizar a abordagem da História dos Intelectuais, uma vez que esse tipo de tratamento de pesquisa leva em consideração ideias, crenças, valores e atitudes, maneiras de pensar e estilos de vida, e os papéis acadêmico-intelectual e social que realizam.

Neste artigo, considerou-se a acepção de Gomes e Hansen (2016) para o entendimento de intelectual. Dessa forma, pensou-se:

[...] a figura do intelectual, como sujeito pensante e agente, ganha centralidade e concretude. Os intelectuais têm um processo de formação e aprendizado, sempre atuando em conexão com outros atores sociais e organizações, intelectuais ou não, e tendo intenções e projetos no entrelaçamento entre o cultural e o político. Nessa acepção, o conceito de intelectual é, como todos os conceitos políticos e sociais, fluído e polissêmico. (GOMES; HANSEN, 2016, p. 12).

No estudo dos intelectuais e de suas ideias pedagógicas ou educacionais, é necessário considerar as "[...] condições de produção político-social das ideias", as "[...] tradições intelectuais, os paradigmas vigorantes em dado contexto cultural, bem como das linguagens e do vocabulário (científico e artístico) disponíveis, além das sensibilidades compartilhadas por indivíduos e grupos intelectuais" (GOMES; HANSEN, 2016, p. 12). Para que a pesquisa apresentasse algumas questões político-sociais, tradições intelectuais, paradigmas em voga e outras particularidades, delimitou-se o recorte temporal durante o período conhecido como a Era Vargas (1930-1945). Compreendeu-se que, durante esse período, houve intelectuais que atuaram em diversas frentes no campo da educação, de forma a impactar ou promover políticas públicas e tendências pedagógicas.

Durante a Era Vargas, houve uma crescente participação de intelectuais nas esferas políticas, inclusive, com influência na elaboração das propostas pedagógicas. De acordo com Cabral e Magalhães (2016), no período intitulado

[...] quadros de intelectuais defensores da escola nova passaram gradativamente a ser integrados nas estruturas sustentadoras das políticas de 
Estado, participando da construção de práticas pedagógicas, associadas a políticas para uma educação de massas que contribuíssem para manter ou modificar conceitos universais e novas ideias exigidas no seio da estrutura social, visando formar um homem novo e garantir a democracia como uma forma de vida exigida pela sociedade moderna. Intelectuais que atuaram nas esferas educacionais de gestão pública, em órgãos de definição de políticas educacionais nacionais e internacionais, na criação de instituições e do conhecimento com base nos ideais escolanovistas. (CABRAL; MAGALHÃES, 2016, p. 171).

As ideias escolanovistas, pautadas nos avanços científicos da Biologia, da Sociologia e da Psicologia, contestavam a educação tradicional vigorada até os finais do século XIX. Os propugnadores buscavam contrapor as práticas pedagógicas antecedentes. No Brasil, tais princípios começam a ganhar destaque em meados dos anos vinte do século XX, enquanto em outros países, já nas décadas finais do século XIX, despontavam com força. Vidal (2003) reitera que muitas das mudanças propostas pelos renovadores da década de 20 já eram praticadas anteriormente, como

[...] a centralidade da criança nas relações de aprendizagem, o respeito às normas higiênicas na disciplinarização do corpo do aluno e de seus gestos, a cientificidade da escolarização de saberes e fazeres sociais e a exaltação do ato de observar, de intuir, na construção do conhecimento do aluno. (VIDAL, 2003, p. 497).

Apesar de alguns preceitos terem sido usados anteriormente, conforme reitera Azevedo (2010), para a apreciação das autoridades nacionais e estrangeiras, a reforma de 1928

[...] marcou, nos domínios da educação, um período revolucionário, não só pelas ideias francamente renovadoras que a inspiraram e que, por ela, entraram em circulação, como pela fermentação de ideias que provocou e pelo estado social que estabeleceu, de trepidação dos espíritos, de sôfregas impaciências e de aspirações ardentes. (AZEVEDO, 2010, p. 704).

As reformas faziam parte de uma tendência internacional na educação. No que tange às intenções do Estado, para além de necessidades sociais, a educação deveria atender às demandas da industrialização, inseridas na produção capitalista. Formar homens que soubessem ler e escrever e controlar o corpo e os hábitos para inserir-se no mercado de trabalho. Por outro lado, segundo Miguel (1997), 
quanto mais os modos de produção e a sociedade tornavam-se mais complexos, mais os trabalhadores das zonas urbanas enxergavam na instituição escolar uma forma de entrada e permanência nas inovações das relações com o trabalho. Dessa maneira, as reformas educacionais tratavam de anseios de políticos, de intelectuais e da própria sociedade.

Partindo dessas premissas, o artigo tem por objetivo identificar alguns estudos que voltaram seus olhares para intelectuais paranaenses que atuaram em prol da Escola Nova, no período da Era Vargas (1930-1945). Os objetivos específicos propostos foram compreender alguns aspectos políticos, econômicos e sociais que ocorreram durante o período da Era Vargas (1930-1945), que se conectaram com as mudanças ocorridas na educação, e identificar alguns estudos que pesquisaram intelectuais paranaenses que atuaram em consonância com os ideais escolanovistas. Para ajudar a atender aos objetivos propostos, a pesquisa possui caráter bibliográfico, fundamentada nos teóricos Miguel (1997); Azevedo (2010); Gomes e Hansen (2016); Cabral e Magalhães (2016).

A metodologia, denominada estado do conhecimento, foi essencial para identificar estudos que se debruçaram acerca das trajetórias de intelectuais paranaenses. Escolheu-se essa metodologia uma vez que as pesquisas do tipo estado do conhecimento ou estado da arte procuram:

[...] mapear e de discutir uma certa produção acadêmica em diferentes campos do conhecimento, tentando responder que aspectos e dimensões vêm sendo destacados e privilegiados em diferentes épocas e lugares, de que formas e em que condições têm sido produzidas certas dissertações de mestrado, teses de doutorado, publicações em periódicos e comunicações em anais de congressos e de seminários. (FERREIRA, 2002, p. 258).

Neste artigo, buscaram-se os estudos das trajetórias de intelectuais paranaenses nos bancos de repertórios de pesquisas. Desse modo, de acordo com Romanowski e Ens (2006), os estudos que se debruçam em apenas um setor de produção e disseminação do conhecimento científico devem ser denominados estado do conhecimento. Justifica-se o estudo tendo em vista a necessidade de tentar intuir, em parte, as relações complexas que atuaram e continuam atuando na educação brasileira, uma vez que "[...] o passado não está atrás ou longe de nós; ele está junto, dentro e, paradoxalmente, próximo a nós, justamente por ter passado. Ele deixa marcas, imagens e sons, enfim, deixa uma herança que não 
pode nem deve ser esquecida" (GOMES, 2013, p. 23). Dessa maneira, a sistematização do conhecimento produzido acerca das trajetórias dos intelectuais contribui para alicerçar novas pesquisas nesse campo, bem como ajuda a identificar agentes que, em meio a relações complexas, ajudam a promover mudanças no campo da educação.

\section{A ERA VARGAS}

Não diferente de outros países da Europa e das Américas, as décadas iniciais do século XX, no Brasil, foram marcadas pela necessidade de proteção das fronteiras, construção do sentimento de nação, pelos projetos de urbanização e fortalecimento das indústrias internas, pela expansão da escolarização elementar, além da centralização do poder do Estado.

Nesse período, mais especificamente com a Revolução de 1930, “[...] começou a chamada Era Vargas, assim conhecida por ser o tempo de construção e consolidação da figura de sua liderança máxima, Getúlio Vargas" (GOMES, 2013, p. 26). A centralização do poder ocorrida nesse período veio com o projeto desenvolvimentista e ganhou força com medidas autoritárias e discursos populistas. O projeto desenvolvimentista de Vargas agregava quatro correntes ideológicas: a centralização do poder, o nacionalismo, o fortalecimento da indústria somado ao antiliberalismo e o positivismo. Nesse ideário, para Fonseca (2012, p. 23):

[...] o desenvolvimento não é apenas uma palavra de ordem a mais, mas o elo que unifica e dá sentido a toda ação do governo, ao legitimar a ampliação de sua esfera nos mais diferentes campos, além da economia propriamente dita: educação, saúde, legislação social, cultura, políticas públicas e etc.

Porém o ideário desenvolvimentista só foi possível por haver um cenário favorável, uma vez que "[...] uma corrente de ideias não existe em abstrato e só faz sentido e justifica sua existência se for capaz de afirmar-se na prática antepondo-se a outra" (HEGEL apud FONSECA, 2012, p. 46). De acordo com Gomes (2012), o discurso e as políticas, pautadas em pensamentos autoritários, encontraram condições de se estabelecer. O período entre guerras mundiais fez com que os países buscassem proteger e manter suas fronteiras econômicas e territoriais. Segundo Gomes (2013), na Era Vargas, período compreendido entre os anos de 1930 e 1945, "[...] modernizar o Brasil era, em síntese, efetivamente conquistar 
seu território e organizar seu povo", dando ao país características industriais, urbanas, modernas e civilizadas (GOMES, 2013, p. 37-42). Tratava-se de prioridade, às autoridades, ordenar a sociedade.

Nos grandes desafios, encontravam-se a saúde precária e a educação da população, investimento em transportes terrestres e marítimos, em meios de comunicação modernos, entre outros. Entre outras particularidades,

[...] até os anos 30, o Brasil era visto como uma sociedade tradicional e atrasada: um país rural, agrário-exportador, com poucas gentes e muitos vazios territoriais a desbravar e ocupar. Pouco desenvolvido econômica e culturalmente, o país vivia dependente de fluxos da economia internacional, como a crise de 1929 acabara de comprovar, mais uma vez; também vivia dependente de ideias vindas do exterior, pois não tinha universidades que formassem suas elites, nem escolas primárias, menos ainda secundárias que educassem seus futuros cidadãos. Grande parte de sua população economicamente ativa, de seus trabalhadores, concentrava-se no campo, sendo pobre ou miserável, além de analfabeta e doente. (GOMES, 2013, p. 43).

De acordo com Razzini (2008), até o final da década de vinte, muitas escolas funcionavam precariamente e, no geral, havia diferenças organizacionais, curriculares e nas modalidades de escola elementar, na extensão de curso, nos programas, nos materiais escolares, nos salários e nos tipos de formação de professores.

Entretanto, em meados dos anos trinta, iniciou-se a transição demográfica brasileira, fato intrinsicamente ligado às transformações dessa sociedade. Uma transição demográfica demarca-se "[...] quando determinadas sociedades se tornam industrializadas, passando a crescer através da combinação da queda das taxas de mortalidade com manutenção de índices estáveis de natalidade" (GOMES, 2013, p. 43). O aumento populacional na Era Vargas, para Gomes (2013), pode ser visto como uma diminuição da mortalidade infantil, somada à manutenção de taxas de fecundidade altas, agregado às novas descobertas científicas e adicionado a novas medidas de saúde pública e saneamento básico.

O aumento da população e o medo do avanço do comunismo impactaram as políticas de imigração. A velha crença no poder do branqueamento da população como índice de avanço civilizatório foi sendo dissolvida por meio da verificação de que a mestiçagem apenas aumentava, além disso, essa mestiçagem passou a ser vista como uma característica do povo brasileiro (GOMES, 2013, p. 51). Renk (2004) reitera que, nos anos que antecederam à Primeira Guerra Mundial, 
intelectuais, políticos e a imprensa brasileira ajudaram a propagar o medo quanto a estrangeiros alemães, devido à possibilidade de a Alemanha ocupar as áreas colonizadas. Por esse ponto de vista, dentre outras coisas, passou-se a priorizar o trabalho de brasileiros em detrimento dos trabalhadores estrangeiros, além de medidas restritivas quanto à entrada de imigrantes.

As leis governamentais para os imigrantes agravaram-se no ano de 1938, "[...] um ano decisivo, no que se refere a medidas de controle de território e de sua ocupação, pois assinala o início da chamada política de nacionalização do Estado Novo" (GOMES, 2013, p. 52). As escolas dos imigrantes foram fechadas, de acordo com Renk (2004), e o ensino pautado na língua de origem, somado à manutenção das tradições e costumes da pátria mãe, foi visto pelo governo Vargas como empecilho para o projeto de unificação nacional.

O nacionalismo foi visto como uma das formas de ordenamento da população brasileira. Dessa forma, apesar de divergências entre intelectuais, escritores e homens públicos, a necessidade de construir uma identidade comum para a população brasileira levou-os a declarar a existência de uma cultura brasileira e um mesmo caráter nacional (DUTRA, 2013, p. 232). De acordo com Renk (2004, p. 112), entendia-se que a "[...] cultura seria uma forma de aglutinar o governo e por meio dela poderia construir a identidade nacional. Assim, o uso da mesma língua, uma história comum, o futebol, o carnaval, o samba eram formas de construir uma identidade nacional". Além disso, os símbolos da pátria, o Hino Nacional e o Hino à Bandeira, foram "[...] elaborados para serem representativos de um passado mítico e glorioso que teria criado a chamada unidade nacional" (SILVA; SILVA, 2014, p. 310).

Para o educador Lourenço Filho, um dos instrumentos disseminadores de uma identidade nacional eram os livros. Lourenço Filho acreditava que a nova proposta para a educação necessitava de mais livros para os diferentes assuntos a serem abordados (DUTRA, 2013, p. 232-3). Nos anos iniciais da década de trinta, a Associação Brasileira de Educação disponibilizou os roteiros de leitura, por meio das coleções da Companhia Editorial.

A essas coleções, emprestaram seus nomes importantes intelectuais, como o educador Anísio Teixeira, no caso da Coleção da Biblioteca do Espírito Moderno, [...] a biblioteca Pedagógica Brasileira, concebida pelo educador Fernando de Azevedo, com cinco séries: Literatura Infantil, Livros Didáticos, Atualidades Pedagógicas, Iniciação Científica e a Brasiliana. Esta última, a 
mais ambiciosa em termos de complexidade intelectual entre as cinco séries, tinha a particularidade de contemplar, exclusivamente, a edição de obras sobre o Brasil, que deveriam proporcionar a seus leitores, segundo seu editor, a mais vasta sistematização de estudos brasileiros. (DUTRA, 2013, p. 243).

Por meio dos livros, nas salas de aula, podia-se ter maior conhecimento das particularidades do país. Essa tomada de consciência cultural, advinda também das instituições escolares, era vista como um instrumento de afirmação da nacionalidade. "O amor à pátria, os valores cívicos e o nacionalismo foram cultivados dentro e fora da sala de aula" (SOUZA, 2008, p. 67). Porém, não só de amor à Pátria viviam os brasileiros.

No que tange às questões econômicas, os anos finais da década de vinte e início da década de trinta vivenciaram a queda na exportação e no preço do café, o que fez com que o governo adotasse como política cafeeira a compra do "estoque existente de café" (ABREU, 2013, p. 184). Segundo Abreu (2013), a desproporção entre a produção e a venda do café fez com que o governo continuasse a comprar safras do produto e viabilizasse o pagamento por meio de recursos orçamentários e taxação das exportações. As medidas de controle cambial, importações e exportações, a crise do café e a eclosão da Segunda Guerra Mundial fizeram com que a demanda se reorientasse para a produção nacional, aumentasse a participação industrial e reduzisse, na mesma proporção, a participação da agricultura.

As medidas governamentais e o aumento demográfico impulsionaram o avanço do processo de urbanização e, junto dele, o de industrialização. Esses fatores estimularam, em detrimento de leis que priorizavam seletos grupos das elites, o Estado a elaborar um amplo e diversificado conjunto de políticas públicas com ênfases sociais, "[...] entre as quais aquelas desenvolvidas pelos novos ministérios da Educação e Saúde, e do Trabalho, Indústria e Comércio (GOMES, 2012, p. 87). O Brasil voltou-se às políticas de massa que atendessem às necessidades do "progresso".

No que tange às medidas quanto ao processo de industrialização, ampliaram-se os direitos dos trabalhadores, bem como passava a ser necessário prepará-los para o mercado de trabalho. Para Fausto (2013), os direitos aos trabalhadores, que começaram a vigorar na década de trinta, auxiliavam o governo a controlar os sindicatos, desmantelar organizações independentes que agiam sob influência dos comunistas, além de proporcionar o reconhecimento de Vargas entre as 
classes populares. Além disso, o interesse do governo em regular as relações com a classe trabalhadora urbana estava pautado em considerações sobre o quadro de crise do capitalismo liberal.

Alguns intelectuais, que se articulavam na política, sabiam o que era necessário para que o projeto fosse bem-sucedido. De acordo com Gomes (2012), Francisco Campos sabia da ameaça de crise, advinda da sociedade de massas, uma vez que ela passava por transformações profundas e numerosas tensões e que estavam "[...] distante da possibilidade de participar de posições políticas que exigiam, crescentemente, formação especializada” (GOMES, 2012, p. 84). Considerando a iminência, Campos conhecia a importância de ter um personagem dotado de grande carga emocional, um mito personificado na figura de Vargas, uma figura que misturava populismo, carisma e personalidade,

[...] a figura do chefe da nação cristalizou-se como a do pai dos pobres, defensor dos humildes, estadista à frente de um Brasil autenticamente brasileiro. Por suas características pessoais, Vargas não era um personagem bem talhado para ser a encarnação desse tipo de governo. Pequeno de altura, ostentava traços de elite (o chapéu gelot, os charutos, o gosto pelo golfe, o desinteresse pelo futebol), e seus discursos eram proferidos em tom solene e monótono. Mas a grande massa viu nele uma figura paternal, cuja estatura e certos traços, em particular o sorriso bondoso, destacavam-se positivamente. A máquina de propaganda encarregou-se de acentuar esses e outros aspectos, a ponto de Vargas ser comumente chamado de o nosso querido baixinho. (FAUSTO, 2013, p. 106).

O cenário era propício ao Golpe de Estado ocorrido em 10 de novembro de 1937. De acordo com Fausto (2013), o contexto era favorável, uma vez que,

[...] os vários setores da classe dominante ansiavam pela ordem e vinham sendo atendidos pelo governo; o aparelho militar e civil, depurados dos que podiam fazer oposição, formava um bloco homogêneo; a grande maioria da elite política preferiria a ditadura ou se conformava com ela; a frágil organização independente dos trabalhadores desaparecera, enquanto crescia nos meios populares o prestígio de Vargas; a esquerda para qual a ditadura começara em 1935, fora praticamente arrasada. Restavam apenas os liberais, cuja fraqueza mais uma vez se revelou. (FAUSTO, 2013, p. 100).

Para aproximar o governo dos interesses privados, além de empréstimos concedidos a industriais, foram criados alguns canais que favoreceram a relação. Dentre eles, 
[...] um dos mais importante foi o Conselho Técnico de Economia e Finanças (CTEF), de 1937, que funcionava como órgão de assessoria do Ministério da Fazenda, visando principalmente à racionalização do sistema tributário, ao disciplinamento dos empréstimos públicos e à padronização dos orçamentos estaduais e municipais. No Conselho do CTEF figuravam vários integrantes da grande indústria. (FAUSTO, 2013, p. 101).

De acordo com Miguel (1997), o processo de industrialização e urbanização no Brasil fez com que o Estado buscasse racionalizar a administração pública, medida que implicou diretamente no sistema educacional. "A educação pública foi vista preponderantemente como instrumento de preparação do homem para a sociedade urbano-industrial e de construção da democracia" (MIGUEL, 1997, p. 12). Dessa forma,

[...] os preceitos de organização racional ligados às ciências que alimentavam a educação condicionaram a experiência da formação de professores primários em novos moldes. Os fundamentos da Pedagogia, enquanto ciência experimental, constituíram um dos pilares da proposta educacional. (MIGUEL, 1997, p. 11).

Nas décadas de 1930 e 1940, a construção da identidade nacional fazia-se mais presente nas propostas curriculares. As propostas curriculares das Escolas Normais atendiam às intencionalidades do Estado, as quais atuaram como instituições específicas para a formação de professores primários. Cabia ao poder público empreender os projetos.

\section{ALGUNS INTELECTUAIS PARANAENSES NO CONTEXTO}

No contexto do processo de industrialização, havia debates entre aqueles que defendiam a escola pública, gratuita, laica e obrigatória e os que viam nessas ideias uma forma de monopolizar a educação. Assim, "[...] mesmo partilhando das novas ideias, uma facção da sociedade brasileira que defendia ideias inspiradas pela Igreja Católica viu na proposta de educação pública, obrigatória e gratuita, a intenção do Estado em monopolizar a educação" (VIEIRA; MIGUEL, 2005, p. 3). Por essa perspectiva, compreende-se que as ideias direcionadas à educação não eram homogêneas.

O Paraná, na primeira metade do século XX, contava com uma população rarefeita e bases econômicas pautadas no beneficiamento da erva-mate, o que 
influenciou na implantação e na consolidação da pedagogia da Escola Nova. De acordo com Miguel (1997), as pesquisas sobre a formação de professores no Paraná permitiram identificar três fases do movimento de reformas inspiradas nas propostas da Escola Nova: início (1920-1938), consolidação (1938-1946) e expansão (1946-1960) dessa tendência pedagógica.

Os cursos superiores auxiliaram na consolidação dos ideais escolanovistas e as universidades foram assumidas como política de Estado, levando à fundação dos cursos de licenciatura no ano de 1936. O Curso de Formação de Professor Secundário do Instituto de Educação da USP (1936) foi pioneiro no Brasil (EVANGELISTA, [s/d]). Quanto ao Paraná, no ano de 1938, foi fundada a Faculdade de Filosofia, Ciências e Letras do Paraná e o Instituto Superior de Educação anexo.

Nos estudos de Ribeiro (2018) acerca da trajetória de formação da professora Pórcia Guimarães Alves - aluna que compôs a primeira turma do Curso de Pedagogia - é possível identificar parte da história da fundação da Faculdade de Ciências do Paraná na perspectiva da docente. Para Pórcia, a fundação da faculdade partiu de um grupo de profissionais que atuavam no meio intelectual e que decidiram completar a estrutura para a universidade. Dentre esses intelectuais, Pórcia descreve a participação do professor Milton Carneiro, Homero de Mello Braga, Carlos de Paula Soares, João Xavier Vianna, Temístocles Linhares e outros que ajudaram a traçar os planos e as estratégias para a fundação da Faculdade de Filosofia, Ciências e Letras do Paraná. Esse grupo procurou, por meio de Osmar Gonçalves da Mota e de seu prestígio junto ao Interventor Federal, Manoel Ribas, conseguir apoio financeiro e colaboração dos agentes ligados aos poderes estatais.

Para os idealizadores da Faculdade de Filosofia, Ciências e Letras do Paraná, de acordo com Campos (2008), a fundação tinha a finalidade de promover um espaço propício para conceber verdadeiros líderes intelectuais, além de disseminar uma sólida formação moral e intelectual. Além disso, a fundação da Faculdade de Filosofia, Ciências e Letras do Paraná representava uma possibilidade de aprofundar conhecimentos científicos advindos da Sociologia, da Biologia e da Psicologia em prol da educação na formação de professores. Dessa maneira, as ações do grupo fundador da Faculdade de Filosofia, Ciências e Letras do Paraná estavam em consonância com o projeto governamental e promoveram a consolidação dos ideais escolanovistas no Paraná. 
Na tentativa de identificar estudos - de mestrado e doutorado - dos intelectuais que auxiliaram no processo de implantação das ideias pedagógicas da Escola Nova no Paraná, durante a Era Vargas, foi consultado o banco de dados da Biblioteca Digital Brasileira de Teses e Dissertações (BDDT), do Instituto Brasileiro de Informação em Ciência e Tecnologia (2017) e o acervo digital Teses \& Dissertações (UFPR). Buscou-se pelos termos intelectual, educadores e educação e, posteriormente, foram focados os trabalhos de intelectuais paranaenses. A pesquisa possibilitou encontrar contribuições de teses e dissertações, cujos resultados estão dispostos na Tabela 1.

Tabela 1 - Pesquisas encontradas por termo

\begin{tabular}{|c|c|c|c|c|c|}
\hline \multirow{3}{*}{ Assunto } & \multirow{3}{*}{ Total } & \multicolumn{4}{|c|}{ Quantidade } \\
\hline & & \multicolumn{2}{|c|}{ Educação } & \multicolumn{2}{|c|}{ História } \\
\hline & & Mestrado & Doutorado & Mestrado & Doutorado \\
\hline Intelectual & 15 & 8 & 4 & 1 & 2 \\
\hline Educadores & 2 & 2 & & & \\
\hline Educação & 903 & 688 & 215 & & \\
\hline TOTAL & 919 & 698 & 219 & 1 & 2 \\
\hline
\end{tabular}

Fonte: As autoras, 2018.

A pesquisa, a partir do termo intelectual, possibilitou localizar 15 produções. Por meio do termo educadores, foram localizadas duas produções em educação e 903 pesquisas ligadas ao termo educação. Em um primeiro momento, foram analisados os títulos dos trabalhos, buscando separar aqueles que potencialmente demonstravam-se relevantes ao estudo. Possivelmente, alguns trabalhos relevantes, que poderiam contribuir com a pesquisa, possam estar fora desse levantamento. Após essa análise, foram selecionadas sete produções acerca da trajetória de intelectuais paranaenses, a saber.

Abordando a questão do envolvimento de intelectuais no cenário paranaense em meados do século XX, a dissertação de Soleni Terezinha Biscouto Fressato (2010), intitulada Pela catolização da elite curitibana: o projeto intelectual do Círculo de Estudos 'Bandeirantes' - CEB 1929-1945, pesquisa os pensadores católicos na fundação do Círculo de Estudos Bandeirantes, em Curitiba. São analisados documentos e periódicos na tentativa de compreender as propostas do projeto intelectual desse grupo. A autora discute a formação do conceito de intelectual 
no contexto histórico brasileiro; enfatiza a preocupação de católicos e inovadores com a educação no intitulado período e aborda o projeto intelectual deles.

A dissertação de Ernando Brito Gonçalves Junior (2011), intitulada 0 impresso como estratégia de intervenção social, versa sobre o cenário intelectual no qual participava Dario Velozzo. Na dissertação, objetivou-se evidenciar a figura de Vellozo como um agente que propôs mudanças no contexto social em que estava inserido e discutir as estratégias de intervenções sociais elaboradas pelo intelectual. Para a elaboração da narrativa, o autor pautou-se em impressos escritos por Dario e procurou perceber como a história e a educação foram utilizadas nos discursos na tentativa de legitimar ideias.

A trajetória elaborada na tese de Dulce Regina Baggio Osinski (2006), intitulada Guido Viaro: Modernidade na arte e na educação, privilegiou a análise da contribuição de Viaro para o ensino da arte no Paraná. Segundo a autora, Viaro foi protagonista de múltiplas ações no campo educacional em Curitiba, principalmente no período compreendido entre a década de 30 até meados dos anos 60 do século XX. A tese objetivou relacionar "[...] o pensamento moderno veiculado na Curitiba da década de 40 e defendido pelos intelectuais da época, com as ideias e ações pedagógicas deste educador em arte" (OSINSKI, 2006). A autora construiu sua tese em três capítulos: o primeiro, que busca analisar o processo de inserção de Guido Viaro no meio cultural paranaense; o segundo, que trata da construção da imagem do artista como um ícone da modernidade local, bem como de suas afinidades com o meio intelectual e sua atuação como professor de ensino superior; o último analisa as relações de Viaro com os demais educadores, que participavam de um mesmo pensamento com relação à importância da arte para o mundo infantil e à culminação da criação do Centro Juvenil de Artes Plásticas. De acordo com a autora, foi nessa instituição que algumas das ideias de Guido foram concretizadas, como, por exemplo, um curso de formação de professores na área específica.

A atuação intelectual e articuladora de Erasmo Pilotto (1910-1992) em favor da Escola Nova, no Paraná, foi analisada na dissertação de Rossano Silva (2009), intitulada $A$ arte como princípio educativo: um estudo sobre o pensamento de Erasmo Pilotto. Na tese intitulada Educação, arte e política: a trajetória intelectual de Erasmo Pilotto, Silva (2014) analisou "[...] as concepções e o papel dado à arte como fundamento da formação cultural da criança e do professor, avaliando 
como, no decorrer de sua trajetória, suas concepções de arte variaram entre a arte tradicional e a moderna, classificadas por Pilotto como 'arte longa' e 'arte breve'" (SILVA, 2014).

Na dissertação intitulada Percursos entre modernidade, João Paulo de Souza Silva (2013) estudou a trajetória intelectual da docente paranaense Eny Caldeira (1912-2002). Na dissertação, o autor procurou tratar das ideias e das ações educativas e modernizadoras de sua pesquisada na década de 50. Ele defende que Caldeira foi uma das personagens de transição na formação do campo educacional no Paraná, momento em que se elevam as "[...] ciências como fonte: Sociologia, Biologia e especialmente a Psicologia como referenciais para o desenvolvimento de novos paradigmas educacionais no Estado e a busca de especialização científica dos quadros docentes" (SILVA, 2013).

Outra dissertação que se debruçou sobre a atuação de uma docente paranaense é Raízes de uma trajetória docente no âmbito de ser mulher, que biografou Olga Mattar. Nessa dissertação, de Rita de Cássia Mattar (2017), é possível identificar alguns personagens que compuseram o quadro de intelectuais que investiram nas ideias da Escola Nova, bem como os professores que se formaram nesses ideais. Além disso, nessa dissertação, pode-se perceber os preconceitos com os quais se debateram os primeiros formandos da Faculdade de Filosofia, Ciências e Letras.

\section{CONSIDERAÇÕES FINAIS}

Após essa breve explanação sobre a Era Vargas, pode-se inferir que a sociedade passava por diversas mudanças e desejava ordenamento. Ao que tudo indica, as políticas da Era Vargas atendiam os anseios dessa população. As medidas políticas adotadas por Vargas influenciavam as diversas estruturas da sociedade de forma orgânica. Dessa forma, as medidas direcionadas à saúde, à indústria, à urbanização, aos meios de comunicação e ao nacionalismo impactaram diretamente nas intuições escolares, bem como as próprias medidas adotadas para o ensino impactaram nas demais medidas. Constatou-se, também, a importância da presença de intelectuais nas esferas políticas. Nessa relação, os intelectuais tanto influenciaram como foram influenciados pelos contextos socioculturais, políticos, econômicos. 
No que tange aos estudos dedicados aos intelectuais que atuaram nesse contexto no Paraná, foram identificados alguns trabalhos que versaram sobre essa temática. Dentre eles, foram estudadas as contribuições dos intelectuais católicos; a atuação de Guido Viaro, Erasmo Pilotto, Dario Velozzo, Eny Caldeira e Olga Mattar. A inexpressividade de trabalhos dedicados a intelectuais paranaenses que atuaram na consolidação das ideias da Escola Nova desvenda possibilidades de novos estudos que versem sobre essa temática.

\section{REFERÊNCIAS}

ABREU, Marcelo de Paiva. O processo econômico. In: SCHWARCZ, Lilia Moritz; GOMES, Angela de Castro; FAUSTO, Boris; PINHEIRO, Letícia; ABREU, Marcelo de Paiva; DUTRA, Eliana de Freitas (Org.). História do Brasil nação - 1808-2010: olhando para dentro. Rio de Janeiro: Objetiva, 2013. V. 4.

AZEVEDO, Fernando de. A cultura brasileira. São Paulo: Edusp, 2010.

CABRAL, Maria Cristina Nunes; MAGALHÃES, Lívia Diana Rocha. Juan Mantovani e Anísio Teixeira: intelectuais da Escola Nova no Brasil e na Argentina. In: SILVA, José Carlos da; BATISTA, Eraldo Leme; SANFELICE, José Luis. História da Educação, Intelectuais e Instituições Escolares. 1. ed. [eletrônica]. Minas Gerais: Navegando Publicações, 2016.

CAMPOS, Névio de. Intelectuais paranaenses e as concepções de universidade (18921950). Curitiba: Editora UFPR, 2008.

DUTRA, Eliana de Freitas. Cultura. In: SCHWARCZ, Lilia Moritz; GOMES, Angela de Castro; FAUSTO, Boris; PINHEIRO, Letícia; ABREU, Marcelo de Paiva Abreu; DUTRA, Eliana de Freitas (Org.). História do Brasil nação: 1808-2010. Olhando para dentro. Rio de Janeiro: Objetiva, 2013. V. 4.

EVANGELISTA, Olinda. A formação universitária do professor: o Instituo de Educação da Universidade de São Paulo (1934-1938). [S.d.].

FAUSTO, Boris. A vida política. In: SCHWARCZ, Lilia Moritz; GOMES, Angela de Castro; FAUSTO, Boris; PINHEIRO, Letícia; ABREU, Marcelo de Paiva; DUTRA, Eliana de Freitas (Org.). História do Brasil nação: 1808-2010: olhando para dentro. Rio de Janeiro: Objetiva, 2013. V. 4.

FERREIRA, Norma Sandra de Almeida. As pesquisas denominadas "estado da arte". Educação \& Sociedade, Campinas, v. 23, n. 79, ago. 2002, p. 257-72. Disponível em: http:// 
www.scielo.br/scielo.php?pid=s0101-73302002000300013\&script=sci_abstract\&tlng=pt. Acesso em: 4 set. 2017.

FONSECA, Pedro Cesar Dutra. Gênese e precursores do desenvolvimentismo no Brasil. In: BASTOS, Pedro Paulo Zahluth; FONSECA, Pedro Cesar Dutra (Org.). A Era Vargas: desenvolvimento, economia e sociedade. São Paulo: Editora UNESP, 2012.

FRESSATO, Soleni Terezinha Biscouto. Pela catolização da elite curitibana: O projeto intelectual do Círculo de Estudos "Bandeirantes" - CEB 1929-1945. 76 f. Dissertação (Mestrado em História) - Universidade Federal do Paraná, Curitiba, 2010.

GOMES, Angela de Castro. Autoritarismo e corporativismo no Brasil: o legado de Vargas. In: BASTOS, Pedro Paulo Zahluth; FONSECA, Pedro Cesar Dutra (Org.). A Era Vargas: desenvolvimento, economia e sociedade. São Paulo: Editora UNESP, 2012.

GOMES, Angela de Castro. As marcas do período. In: SCHWARCZ, Lilia Moritz; GOMES, Angela de Castro; FAUSTO, Boris; PINHEIRO, Letícia; ABREU, Marcelo de Paiva Abreu; DUTRA, Eliana de Freitas (Org.). História do Brasil nação: 1808-2010. Olhando para dentro. Rio de Janeiro: Objetiva, 2013. V. 4.

GOMES, Angela de Castro; HANSEN, Patricia Santos. Intelectuais mediadores: práticas culturais e ação política. Rio de Janeiro: Civilização Brasileira, 2016.

GONÇALVES JUNIOR, Ernando Brito. O impresso como estratégia de intervenção social. 106 f. Dissertação (Mestrado em Educação) - Universidade Federal do Paraná, Curitiba, PR, 2011.

INSTITUTO BRASILEIRO DE INFORMAÇÃO EM CIÊNCIA E TECNOLOGIA. Biblioteca Digital Brasileira de Teses e Dissertações. 2016. [Banco de dados]. Disponível em: http://bdtd. ibict.br/vufind/. Acesso em: 9 set. 2017.

MATTAR, Rita de Cássia. Raízes de uma trajetória docente no âmbito de ser mulher. 164 f. Dissertação (Mestrado em Educação) - Pontifícia Universidade Católica do Paraná, Curitiba, PR, 2017.

MIGUEL, Maria Elisabeth Blanck. A formação do professor e a organização social do trabalho. Curitiba: Editora UFPR, 1997.

OSINSKI, Dulce Regina Baggio. Guido Viaro: modernidade na arte e na educação. Orientador: Carlos Eduardo Vieira. 391 f. Tese (Doutorado em Educação) - Universidade Federal do Paraná, Curitiba, 2006. 
RAZZINI, M. de P. G. Instrumentos de escrita na escola elementar: tecnologias e práticas. In: MIGNOT, A. C. V. (Org.). Cadernos à vista: escola, memória e cultura escrita. Rio de Janeiro: EDUERJ, 2008. p. 91-113.

RIBEIRO, Alexandra Ferreira Martins. Adentrando aos arquivos: formação e aspectos da atuação docente de Pórcia Guimarães Alves (1917-1962). 200 f. Dissertação (Mestrado em Educação) - Pontifícia Universidade Católica do Paraná, Curitiba, 2018.

RENK, Valquiria Elita. A educação dos imigrantes alemães católicos em Curitiba. Curitiba: Champagnat, 2004.

ROMANOWSKI, Joana Paulin; ENS, Romilda Teodora. As pesquisas denominadas do tipo "Estado da Arte" em Educação. Revista Diálogo Educacional, Curitiba, v. 6, n. 19, set./ dez. 2006, p. 37-50. Disponível em: http://redalyc.uaemex.mx/src/inicio/ArtPdfRed. jsp?iCve=189116275004. Acesso em: 14 mar. 2017.

SILVA, João Paulo de Souza. Percurso entre modernidades. 190 f. Dissertação (Mestrado em Educação) - Universidade Federal do Paraná, Curitiba, 2013.

SILVA, Rossano. A arte como princípio educativo: um estudo sobre o pensamento de Erasmo Pilotto. 171 f. Dissertação (Mestrado em Educação) - Universidade Federal do Paraná, Curitiba, 2009.

SILVA, Rossano. Educação, arte e política: a trajetória intelectual de Erasmo Pilotto. Orientador: Carlos Eduardo Vieira. 341 f. Tese (Doutorado em Educação) - Universidade Federal do Paraná, Curitiba, 2014.

SILVA, Vanderlei; SILVA, Maciel Henrique. Dicionário de conceitos históricos. São Paulo: Editora Contexto, 2014.

SOUZA, Rosa Fátima. História da organização do trabalho escolar e do currículo no século XX: ensino primário e secundário no Brasil. São Paulo: Cortez Editora, 2008.

UNIVERSIDADE FEDERAL DO PARANÁ. Teses \& dissertações. 2016. (Banco de dados). Disponível em: http://acervodigital.ufpr.br/handle/1884/284. Acesso em: 9 out. 2017.

VIDAL, Diana Gonçalves. Escola Nova e processo educativo. In: LOPES, Eliane Marta, FIGUEIREDO, Luciano; GREIVAS, Cynthia (Org.). 500 anos de educação no Brasil. Belo Horizonte: Autêntica, 2003.

VIEIRA, Alboni Marisa Dudeque Pianovski; MIGUEL, Maria Elisabeth Blanck. A Escola Nova no Paraná: avanços e contradições. Revista Diálogo Educacional, Curitiba, v. 5, n. 
14, p. 93-100, jan./abr. 2005. Disponível em: http://www2.pucpr.br/reol/pb/index.php/ dialogo?dd99=issue\&dd0=58. Acesso em: 21 out. 2017.

VIÑAO, Antonio Frago. Historia de la educación y historia cultural - posibilidades, problemas, cuestiones. Revista Brasileira de Educação, n. 0, set./dez. 1995, p. 63-82. Disponível em: http://www.anped.org.br/sites/default/files/rbe/files/rbe_0.pdf. Acesso em: 10 jan. 2018.

\section{Sobre as autoras:}

Alexandra Ferreira Martins Ribeiro: Doutoranda em Educação pela Pontifícia Universidade Católica do Paraná (PUCPR). Mestre em Educação, linha de pesquisa História, Memória e Políticas da Educação pela PUCPR. Bolsista CAPES. Especialização em MBA em Gestão Financeira, Controladoria e Auditoria, (2004), concedida por meio do Instituto Superior de Administração e Economia Fundação Getúlio Vargas, FGV/ISAE. Bacharel em Administração de Empresas e Licenciada em História pela PUCPR. E-mail: alexandrafmribeiro@gmail.com

Alboni Marisa Dudeque Pianovski Vieira: Graduação em Direito pela Universidade Federal do Paraná (UFPR). Licenciatura em Pedagogia e mestrado em Educação pela Pontifícia Universidade Católica do Paraná (PUC-PR). Mestrado em Gestão de Instituições de Educação Superior pela Universidade Tuiuti do Paraná e doutorado em Educação pela PUC-PR. Professora do curso de Pedagogia e do Programa de Pós-Graduação em Educação- Mestrado e Doutorado da PUC-PR, dos cursos de especialização da UFPR (PECCA) e da Escola da Magistratura do Paraná (EMAP). Experiência na área de Educação, com ênfase em história da educação, políticas públicas e formação de professores. E-mail: alboni@alboni.com

\section{Recebido em: março de 2018}

Aceito em: dezembro de 2018 
